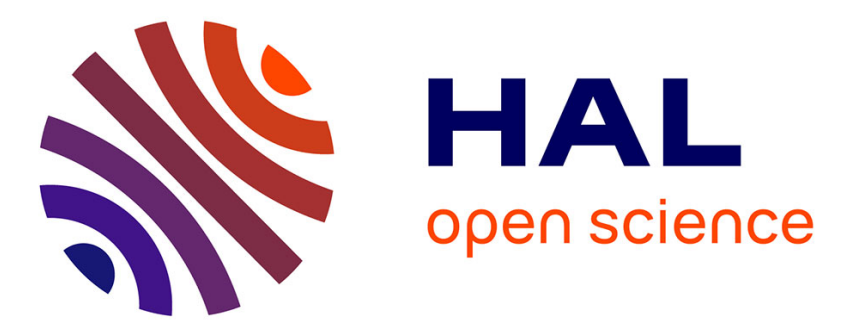

\title{
Using airborne thermal inertia mapping to analyze the soil spatial variability at regional scale
}

\author{
I. Cousin, C. Pasquier, Maud Seger, A. Tabbagh
}

\section{To cite this version:}

I. Cousin, C. Pasquier, Maud Seger, A. Tabbagh. Using airborne thermal inertia mapping to analyze the soil spatial variability at regional scale. Globalsoilmap : basis of the gloabl spatial soil information system: Proceedings of the 1rst Global soilmap conference, Oct 2013, Orléans, France. pp.441-446. hal-01142106

\section{HAL Id: hal-01142106 https://hal.sorbonne-universite.fr/hal-01142106}

Submitted on 14 Apr 2015

HAL is a multi-disciplinary open access archive for the deposit and dissemination of scientific research documents, whether they are published or not. The documents may come from teaching and research institutions in France or abroad, or from public or private research centers.
L'archive ouverte pluridisciplinaire HAL, est destinée au dépôt et à la diffusion de documents scientifiques de niveau recherche, publiés ou non, émanant des établissements d'enseignement et de recherche français ou étrangers, des laboratoires publics ou privés. 


\title{
Using airborne thermal inertia mapping to analyze the soil spatial variability at regional scale
}

\author{
I. Cousin, C. Pasquier \& M. Séger \\ INRA, UR0272 SOLS, Orléans, France
}

A. Tabbagh
UMR 7619 Sisyphe, Paris, France

ABSTRACT: This study aims at demonstrating the ability of thermal airborne remote sensing to help in delineating soil types over large areas. Measurements of the surface temperature variations were compared with electrical resistivity measurements recorded for three depths of investigation. The study area was located in the Beauce region with Calcisols and Cambisols, 0.3 to $1.2 \mathrm{~m}$ thick. Airborne thermal measurements were recorded by the ARIES radiometer in the 10.5-12.5 $\mu \mathrm{m}$ thermal infra-red channel, on December $11^{\text {th }} 2002$. Comparisons between thermal airborne data and electrical resistivity measurements demonstrated that: the spatial organisation of the thermal inertia map resembles the spatial organisation of the $0-170 \mathrm{~cm}$ resistivity map, suggesting that the investigation depth of the two methods is similar; the thermal inertia values were significantly different between the Calcisols and the Cambisols. In the Beauce area, the thermal inertia map would then consist of a useful tool to characterize the soil spatial variability with a high spatial resolution.

\section{INTRODUCTION}

To describe soil physical characteristics on surface areas, a wide panel of remote sensing and ground based methods has been developed: remote sensing, in the visible and radar domains enable the estimation of soil parameters over large areas but they are often limited to the estimation of parameters of the soil surface or the soil surface horizon. On the contrary, ground based methods, like electrical resistivity or EMI methods, enable to derive soil parameters for the whole soil thickness, i.e. down to about $2 \mathrm{~m}$. Nevertheless, they can hardly be run over large areas of several square kilometers if we intend of keeping a correct resolution of information over the 1 to 2 meters soil depth. The present study focuses on the thermal airborne remote sensing method. It is supposed to investigate over the whole soil thickness, and can cover large areas of several square kilometers. To evaluate the depth of investigation of the method, this concept being understood as the thickness of the soil layers taken into account in a measurement-, the measurements of the surface temperature variations will be compared with electrical resistivity measurements recorded for three increasing depths of investigation. To determine the pedological parameters that influence the thermal airborne remote sensing method data, the latter will be compared to local measurements of some pedological characteristics.

\section{THE SOIL SURFACE TEMPERATURE EVOLUTION}

The absolute value of the surface temperature of a bare soil depends on several parameters that determine the heat balance at ground surface. They cannot be controlled but lateral changes in the ground thermal properties may generate variations in surface temperature that can be measured. The latter are related to the ability of the heat to be moved downward or upward by the subsoil. For a homogeneous solid and unsteady heat inputs, the temperature changes are inversely proportional to the thermal inertia, and it is thus usual to discuss the results of a thermal prospection in terms of variations in apparent thermal inertia (Price, 1977) of the soil. It is of great importance to evaluate the conditions under which the depth of investigation of the method will overpass the first layer (Scollar et al., 1990). This depth does not depend on the choice of a frequency or of other instrument parameters but on the history of the heat exchange at the soil surface before the measurement time: if the duration of a transient input of heat (respectively output) lasts one or two days, the depth of investigation would be limited to about $25 \mathrm{~cm}$; it would reach about $1 \mathrm{~m}$ if the transient input lasts one week or more. The soil temperature has then to be monitored for several days to de- 
termine the most adequate period for an airborne flight dedicated to thermal inertia measurements. Finally, the compaction also strongly influences the thermal properties of the soil, but we hypothesize that tillage would have homogenized the soil surface temperature of bare soil.

\section{METHODS}

\subsection{Study site}

The study site was located in the Beauce region (France), on a cultivated field of 110 ha. About 300 auger holes were dug to characterize the soils (Figure 1). The soils consisted of a loamy-clay layer developed over the Beauce limestone bedrock or the cryoturbed or soft limestone deposits. They were haplic Calcisols or calcaric Cambisols (IUSS Working Group WRB, 2006), and were classified into several soil units according to i) the bedrock where they have developed (cryoturbated or not), ii) the thickness of the loamy-clay layer (Figure 1), and iii) the volume proportion of rock fragments (Nicoullaud et al., 2004) (Figure 2). In the following, two spatial plots (plot A in the North-East and plot B in the South-West) will be considered in this study.

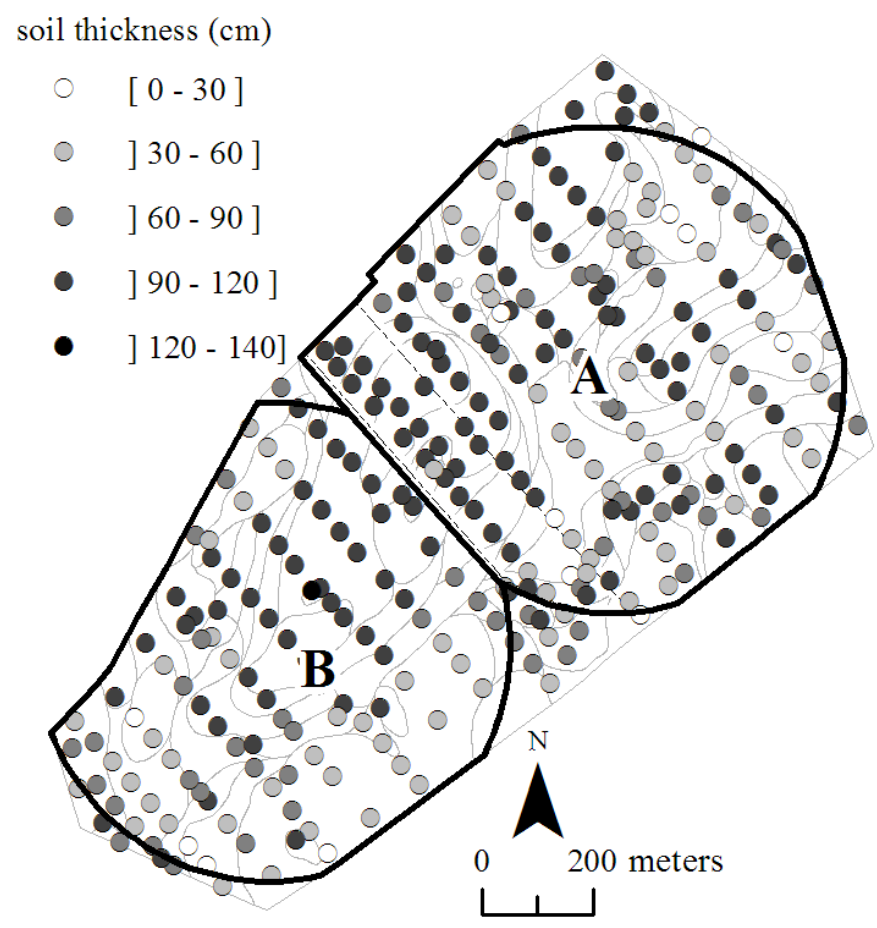

Figure 1. Localization of the auger holes and soil thickness measured at each auger hole. The lines delineate the soil types (see Figure 2)
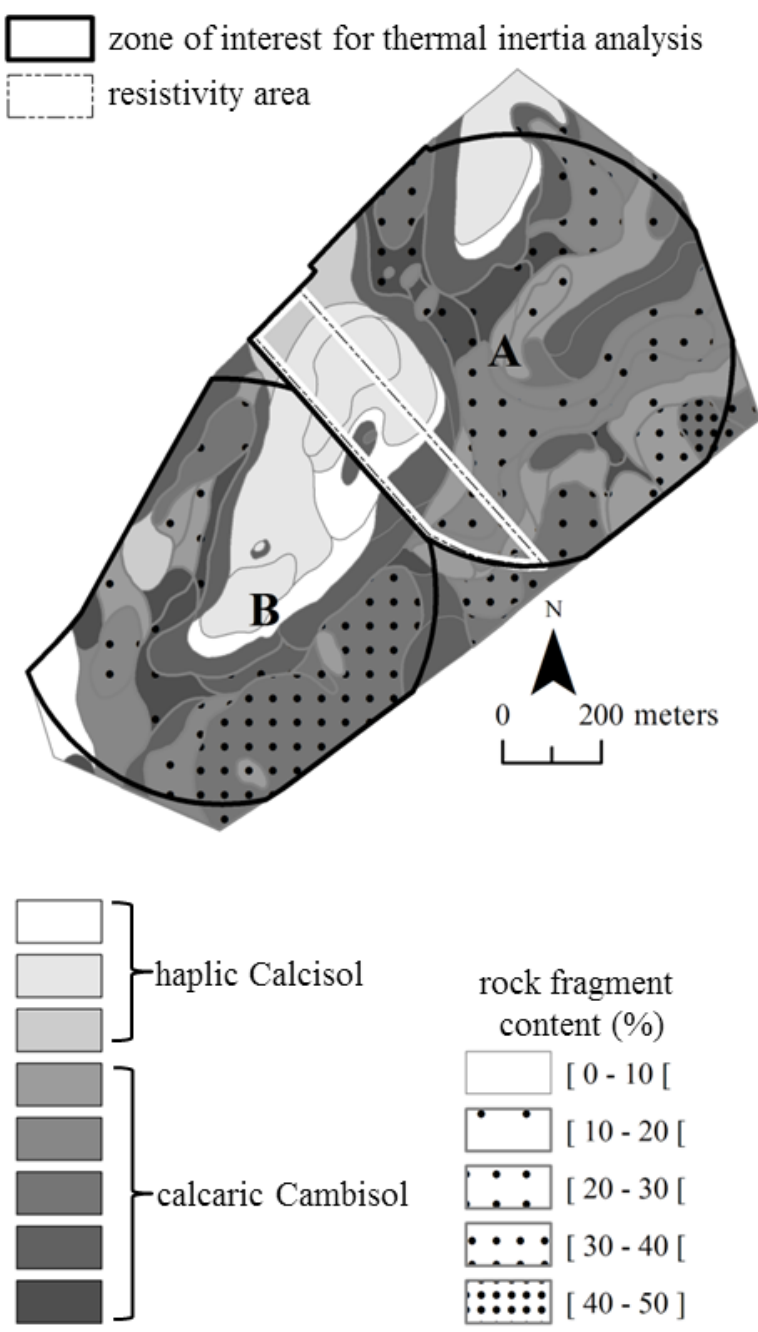

Figure 2. Soil map of the studied area. The electrical resistivity area and the zone of interest for the thermal inertia analysis are delineated.

\subsection{Electrical resistivity measurements}

On a subplot of the plot A, electrical resistivity measurements were obtained at the field scale (see the location in Figure 2) by the use of the ARP(C device (Panissod et al., 1997), which is a mobile soil electrical resistivity mapping system, that comprises a multi-probe system of three arrays (V1, V2, V3 arrays) pulled by a cross-country vehicle. The distance between the current injection electrodes and measurement electrodes, and the distance between two electrodes for a given array are about $0.5 \mathrm{~m}$ for the V1 array, about $1 \mathrm{~m}$ for the V2 array and about 1.7 $\mathrm{m}$ for the V3 array. A resistivity meter injects $10 \mathrm{~mA}$ at $122 \mathrm{~Hz}$ and it is associated to a Doppler radar which triggers a measurement every $0.1 \mathrm{~m}$ along the electrical transect. The electrical measurements then consist of apparent resistivity measurements for three pseudo-depths. All the measurements were georeferenced and recorded on a PC. The electrical resistivity measurements with the ARP $\odot$ device were recorded in August 2012, during summer, after harvest. 


\subsection{Airborne thermal inertia measurements}

The thermal measurements were recorded by an ARIES radiometer that includes two numerical channels, one in the visible and near infra-red range (0.5-1 $\mu \mathrm{m})$ and one in the thermal infra-red range (10.5-12.5 $\mu \mathrm{m})$ (Monge \& Siriou, 1975). Two internal blackbodies allow translating the recorded video signal in brightness temperature. The data acquisition took place on December 11, 2002 at $10 \mathrm{~h} 40$ U.T. with a flight altitude of $1006 \mathrm{~m}$, an 'Instantaneous Field Of View' of $2.82 \mathrm{~m}$ at nadir. As demonstrated by Tabbagh (1977), morning flights are advised, since superficial effects due to diurnal flux variations are minimized. The sampling step along a line was equal to $1.75 \mathrm{~m}$. The mirror rotated at 36.4 $\mathrm{Hz}$ and the speed of the plane was $56.6 \mathrm{~m} . \mathrm{s}^{-1}$. The data were corrected for pitch and roll using data from the gyroscope. After the flight, the anamorphic distortion was corrected and a last geometric rectification was done in the GIS.

By using the algorithm described in Scollar et al. (1990), the heat flux variations at the soil surface were calculated from the soil temperature data recorded between the 15th November 2002 and the 15th December 2002 at the nearby Bricy meteorological station at 10, 20, 50 and $100 \mathrm{~cm}$ depth. The cooling of the soil was significant during this period, especially in the six days preceding the flight. The depth of investigation can thus be considering as greater than the thickness of the ploughed layer and we assume that the surface temperature reflect the thermal inertia of the subsoil. The video values were translated in terms of apparent thermal inertia values of the soil horizon below the topsoil by assuming a 1.2 $\mathrm{W} \mathrm{m} \mathrm{m}^{-1} \mathrm{~K}^{-1}$ conductivity, a $0.48 \mathrm{~m}^{2} \mathrm{~s}^{-1}$ diffusivity (1732 S.I. thermal inertia) and a 25 thickness for the top ploughed layer. On December 2002, the plot A exhibited bare soils, whereas residuals of vegetal straws covered the soils in plot B.

\subsection{Comparison between airborne thermal inertia measurements, electrical resistivity measurements and auger holes data.}

A spatial correlation analysis was computed to compare apparent thermal inertia measurements and apparent electrical resistivity measurements on the subplot of the plot A.

On each parcel of the study area, a principal component analysis was conducted to define the pedological characteristics that would be the most influent on the airborne thermal inertial measurements. To deal with the very local measurements on the auger holes compared to the resolution of the thermal inertia map, we have determined the median value of thermal inertia over a $5 \mathrm{~m}$ circle area, centered at the position of each auger hole.

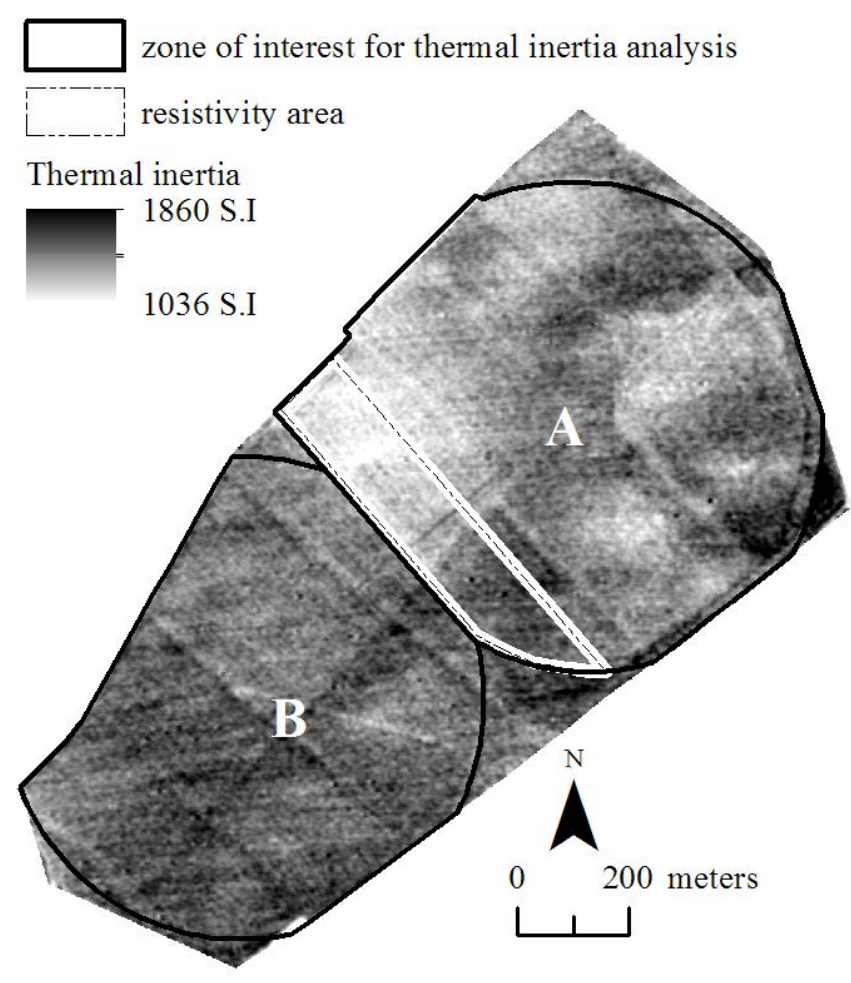

Figure 3. Apparent thermal inertia of the subsoil layer deduced from brightness temperature in the 10.5 - $12.5 \mu \mathrm{m}$ channel.

\section{RESULTS}

\subsection{The thermal inertia map}

The thermal inertia map derived from the airborne measurements on December $11^{\text {th }} 2002$ demonstrates that it varies from 1036 to 1860 S.I. over the studied area (Figure 3). It also exhibits a spatial organization, with higher values in the plot $B$ than in the plot A. In the plot B, linear structures that could be of anthropic origin, can be observed. On the contrary, in the plot A, the structure of the signal does not resemble to regular structures and could be related to natural structures linked to the soil organization.

\subsection{Comparison with the electrical resistivity measurements and discussion about the investigation depth}

The electrical resistivity measurements were recorded on a subplot of the plot A (Figure 4). The three arrays exhibited a similar spatial organization, with higher values in the South-East part and lower values in the North-West part. As expected, they were strongly correlated (Table 1). 
Table 1. Pearson correlation coefficients between the three arrays of electrical resistivity and the thermal inertia measurements.

\begin{tabular}{ccccc}
\hline & $\begin{array}{c}\text { Thermal } \\
\text { inertia }\end{array}$ & V1 array & V2 array & V3 array \\
\hline $\begin{array}{c}\text { Thermal } \\
\text { inertia }\end{array}$ & 1 & & & \\
V1 array & 0.57 & 1 & & \\
V2 array & 0.65 & 0.91 & 1 & \\
V3 array & 0.66 & 0.77 & 0.92 & 1 \\
\hline
\end{tabular}
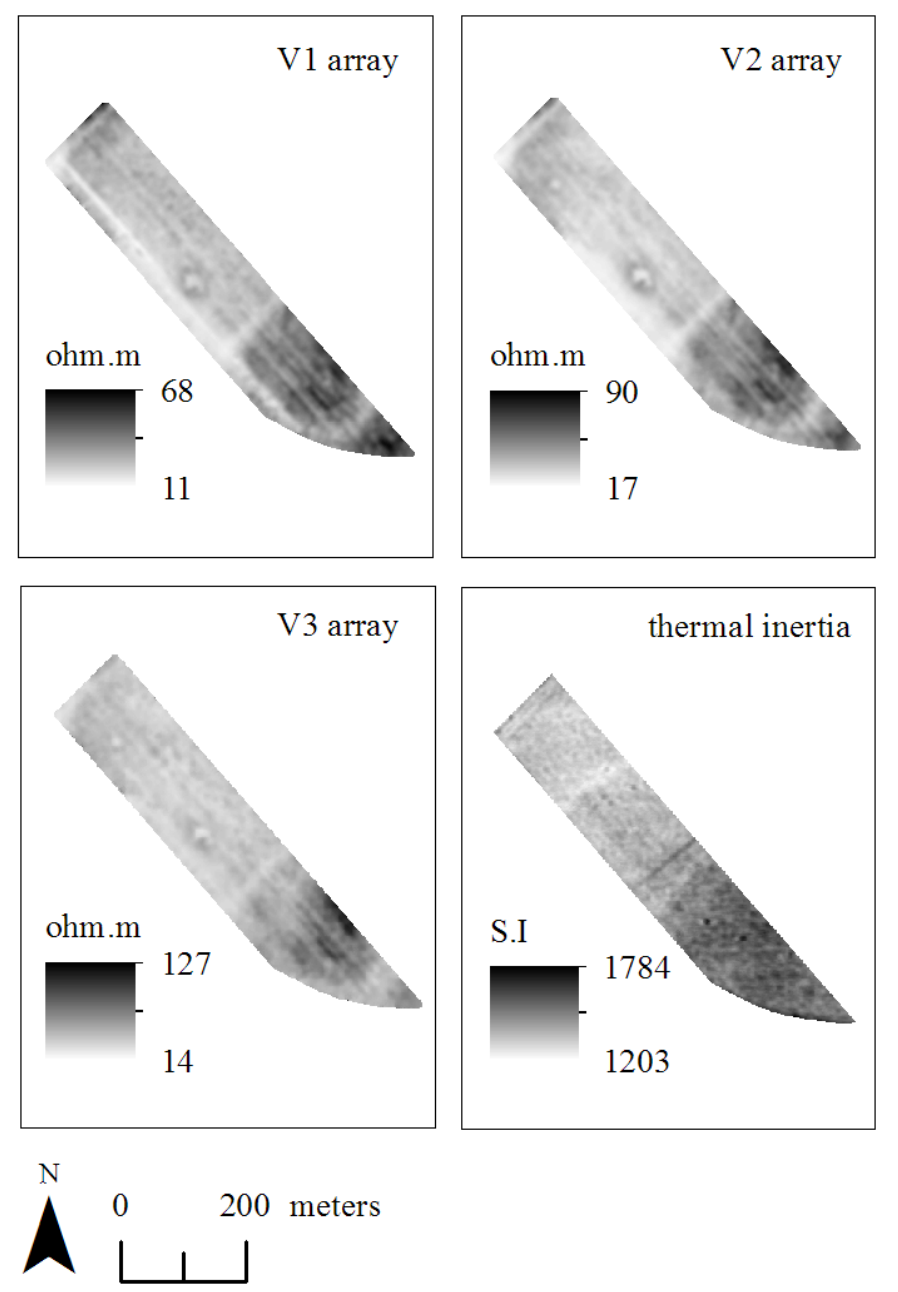

Figure 4. Electrical resistivity maps for the V1, V2 and V3 arrays on the subplot of the parcel A. Comparison with the thermal inertia measurements in the same area.

The thermal inertia map showed a similar spatial organization, with higher values in the South-East part and lower values in the North-West part. The correlation between thermal inertia measurements and electrical resistivity was higher with the V3 array (Table 1). Both electrical resistivity measurements and thermal inertia measurements were thus sensitive to the same pedological characteristics. The higher correlation with the V3 array suggests that the depth of investigation of the airbone thermal meas- urements could be the same as the V3 array, say of about $1.70 \mathrm{~m}$.

\subsection{Influence of pedological data and soil types on the airborne thermal measurements}

As airborne thermal inertia measurements seem to be better correlated to the V3 array and would thus explore about $1.7 \mathrm{~m}$ depth, we have analyzed the relationships between, on the one hand, the thermal inertia measurements, and on the other hand, the soil depth, the soil lime content, and the rock fragments contents because they are highly variable over the whole soil thickness in the studied area. On the plot A, with bare soils, the principal component analysis demonstrated that the thermal inertia was wellcorrelated to the soil thickness, the rock fragment content and the lime content with equivalent correlation coefficients (Figure 5, Table 2). Despite being significant also, the correlations coefficient were lower significant for the plot $\mathrm{B}$, whose soils were partly covered by vegetal straws, especially as far as soil thickness is concerned (Figure 6, Table 3). In the PCA analysis, the thermal inertia was indeed associated to the F2 axis, whereas the pedological characteristics were associated to the F1 axis.

Table 2. Pearson correlation coefficients between some pedological characteristics and the thermal inertia measurements for the plot A. (number of observations: 159).

\begin{tabular}{lcccc}
\hline & $\begin{array}{c}\text { Soil } \\
\text { thickness }\end{array}$ & $\begin{array}{c}\text { Lime } \\
\text { content }\end{array}$ & $\begin{array}{c}\text { Stone } \\
\text { content }\end{array}$ & $\begin{array}{c}\text { Thermal } \\
\text { inertia }\end{array}$ \\
\hline $\begin{array}{l}\text { Soil } \\
\text { thickness }\end{array}$ & 1 & & & \\
\hline $\begin{array}{l}\text { Lime } \\
\text { content }\end{array}$ & -0.28 & 1 & & \\
\hline $\begin{array}{l}\text { Stone } \\
\text { content }\end{array}$ & -0.43 & 0.69 & 1 & \\
\hline $\begin{array}{l}\text { Thermal } \\
\text { inertia }\end{array}$ & -0.50 & 0.50 & 0.50 & 1 \\
\hline
\end{tabular}

Table 3. Pearson correlation coefficients between some pedological characteristics and the thermal inertia measurements for the plot B. (number of observations: 105).

\begin{tabular}{lcccc}
\hline & $\begin{array}{c}\text { Soil } \\
\text { thickness }\end{array}$ & $\begin{array}{c}\text { Lime } \\
\text { content }\end{array}$ & $\begin{array}{c}\text { Stone } \\
\text { content }\end{array}$ & $\begin{array}{c}\text { Thermal } \\
\text { inertia }\end{array}$ \\
\hline $\begin{array}{l}\text { Soil } \\
\text { thickness }\end{array}$ & 1 & & & \\
\hline $\begin{array}{l}\text { Lime } \\
\text { content }\end{array}$ & -0.41 & 1 & & \\
\hline $\begin{array}{l}\text { Stone } \\
\text { content }\end{array}$ & -0.51 & 0.81 & 1 & \\
\hline $\begin{array}{l}\text { Thermal } \\
\text { inertia }\end{array}$ & -0.16 & 0.32 & 0.26 & 1 \\
\hline
\end{tabular}


F1 and $F 2,81 \%$ of the total variance

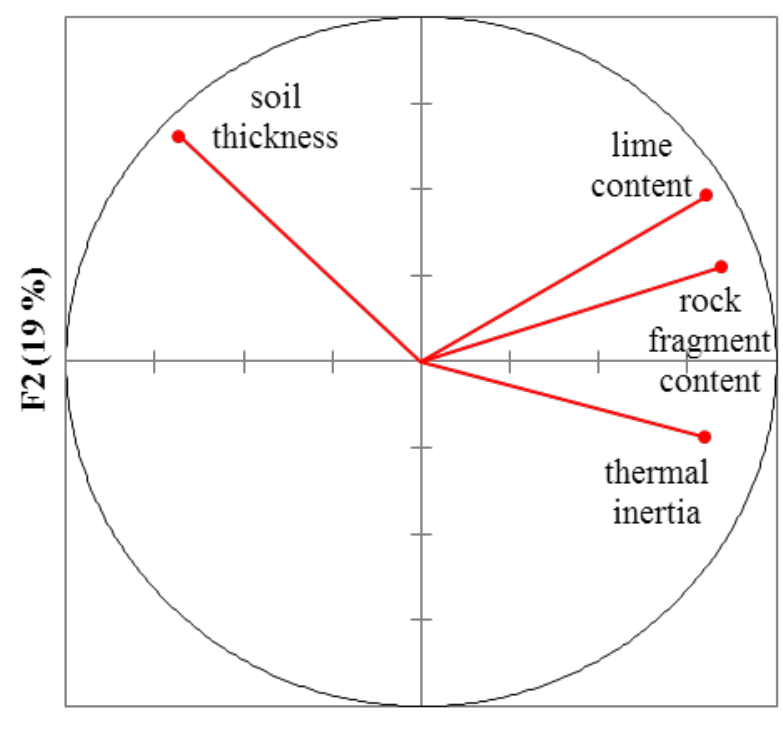

F1 $(62 \%)$

Figure 5. Principal component analysis with the airborne thermal inertia data and some pedological characteristics for the plot A.

$F 1$ and $F 2,80 \%$ of the total variance

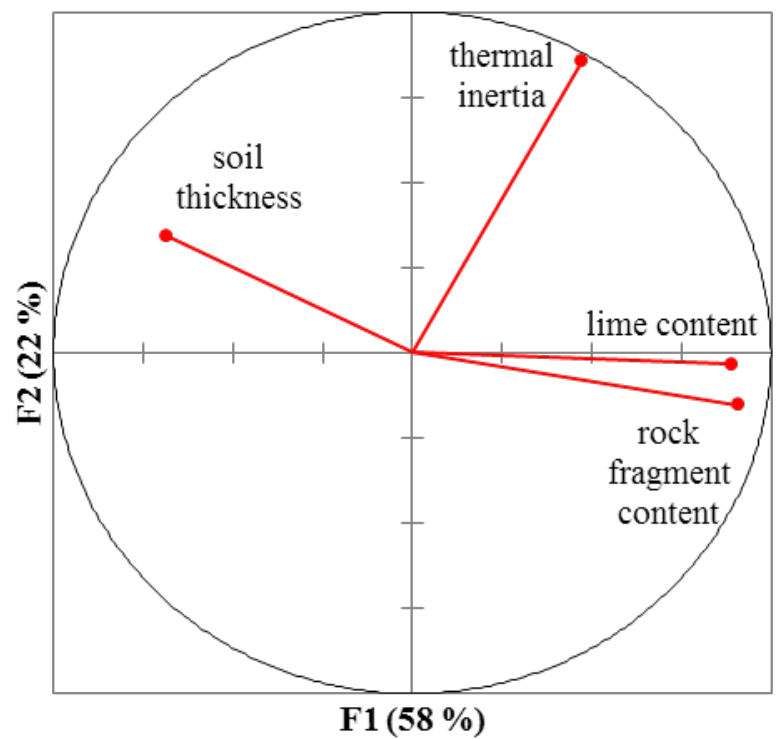

Figure 6. Principal component analysis with the airborne thermal inertia data and some pedological characteristics for the plot A.

A statistical analysis was then conducted on the thermal inertia values on the two main soil types, say the Calcisols and the Cambisols (Figure 7). It demonstrated that, for the plot A the haplic Calcisols, that were calcareous, deep and contained only a small quantity of rock fragments, had thermal inertia values significantly different than the values for the calcaric Cambisols, that were thinner and contained significant quantities of rock fragments. For the plot $\mathrm{B}$, the differences between the thermal inertia values between the Calcisols and the Cambisols

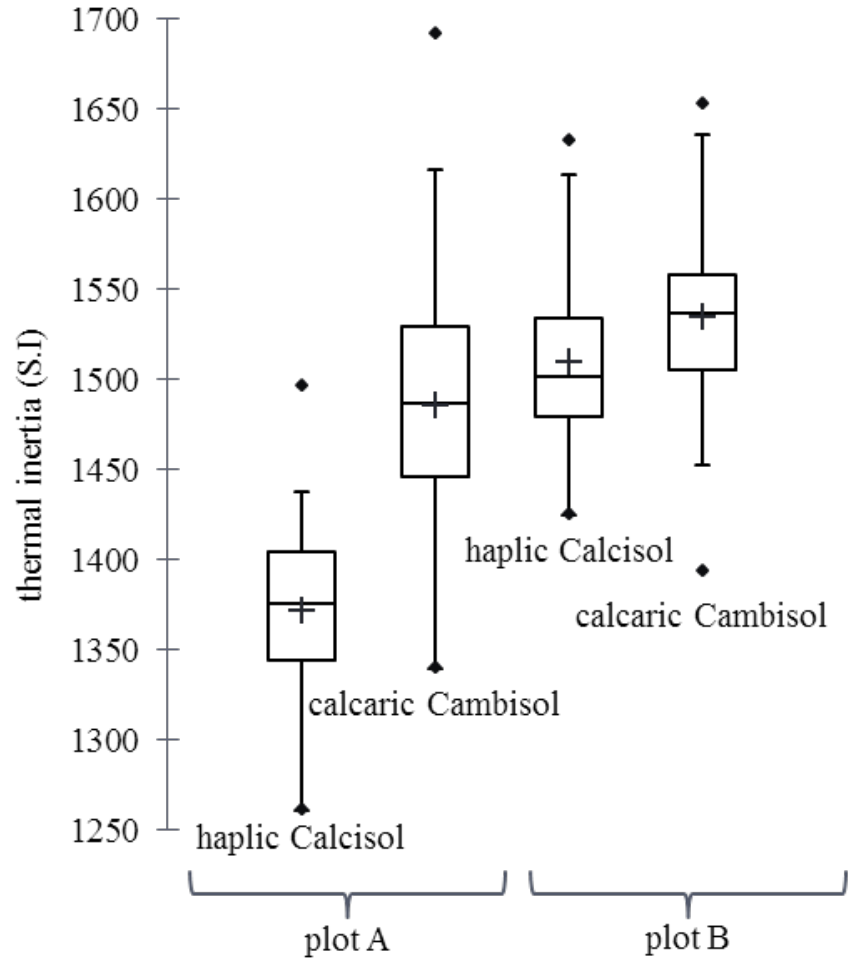

Figure 7. Comparison between the airborne thermal inertia data and the two soil types on the studied area for both the plots A and $\mathrm{B}$.

were lower but remained significant. We can then conclude that the thermal inertia measurements seem to be efficient to discriminate between soil types, when the thermal prospection has been conducted on bare soils.

\section{CONCLUSION}

In this study case in the Beauce area, airborne thermal inertia mapping has demonstrated its ability to evidence the difference between two types of soils, that exhibit differences in soil stone content, lime content, soil thickness and degree of weathering of the calcareous on which soil have developed. In this study area, thermal inertia measurements and electrical resistivity measurements with an inter-electrode spacing of $1.70 \mathrm{~m}$ were influenced by the same pedological characteristics, and it appears as believable that the depth of investigation obtained for the December 2002 airborne thermal inertia experiment was comparable with the one of the V3 array of the ARP $\odot$ multi-depth system. Investigations have then to be continued to i) generalize these results to other contexts and ii) identify the optimum soil conditions to realize an airborne thermal inertia measurements campaign. The prospections should indeed be conducted when soil has been cooled (or warmed) for several days before the prospection, and when soils are not cover by straws. Despite these limitations, due to the spatial resolution of the measurement - of the order of 2 meters - and the possibility to cover 
large areas of several square kilometers, airborne thermal inertia measurements appear as a promising tool to help in delineating soil characteristics and soil types in the Global Soil Map context.

\section{REFERENCES}

IUSS Working Group WRB. 2006. World reference base for soil resources 2006. World Soil Resources Reports No. 103. FAO, Rome.

Monge, J.L. \& Siriou, R. 1975. ARIES: un radiomètre multicanal à balayage. 5th Spatial Optics meeting, Société Française d'Optique, Marseille, June 1975, library of L.M.D, Ecole polytechnique, 91128 Palaiseau, France, 14 pp.

Nicoullaud, B., Couturier, A., Beaudoin, N., Mary, B., Coutadeur, C. \& King, D. 2004. Modélisation spatiale à l'échelle parcellaire des effets de la variabilité des sols et des pratiques culturales sur la pollution nitrique agricole. In: Organisation spatiale des activités agricoles et processus environnementaux. P. Monestiez, S. Lardon, B. Seguin (eds). Coll. Science Update, INRA Editions: 143-161.

Panissod, C., Dabas, M., Jolivet, A. \& Tabbagh, A. 1997. A novel mobile multipole system (MUCEP) for shallow (0$3 \mathrm{~m})$ geoelectrical investigation: the 'Vol-de-canards' array. Geophysical Prospecting 45: 983-1002.

Price J. C., 1977. Thermal inertia mapping: a new view of the earth. Journal of Geophysical Research 82-18: 2582-2590.

Scollar, I., Tabbagh, A., Hesse, A. \& Herzog, I. 1990. Archaeological prospecting and remote sensing. Cambridge University Press, 674p.

Tabbagh, A. 1977. Sur la détermination du moment de mesure favorable et l'interprétation des résultats en prospection thermique archéologique. Annales de Géophysique 33: 243254. 